\title{
Money may buy happiness, but often so little that it doesn't matter
}

Reference: Boyce, C. J., Daly, M., Hounkpatin, H. O., \& Wood, A. M. (2016). Money may buy happiness, but often so little that it doesn't matter. Psychological Science.

Final version as submitted, pre-proofing, the copy of record and copyright reside with the journal. This article may not exactly replicate the final version published in the APS journal. It is not the copy of record.

Authors: Christopher Boyce ${ }^{1}$, Michael Daly ${ }^{12}$, Hilda Osafo Hounkation ${ }^{3}$, Alex M. Wood $^{14}$

${ }^{1}$ Behavioural Science Centre, Stirling Management School, University of Stirling, Scotland.

${ }^{2}$ UCD Geary Institute, University College Dublin, Belfield, Dublin 4, Ireland.

${ }^{3}$ School of Medicine, University of Southampton, England.

${ }^{4}$ School of Psychological Sciences, University of Manchester, England.

We thank Liam Delaney for helpful comments. We thank the UK Data Archive for providing access to the data and the ESRC for providing funding (ES/K00588X/1). Correspondence concerning this article should emailed to christopher.boyce@stir.ac.uk 
Money may buy happiness, but often so little that it doesn't matter

Whether money buys happiness or not is a question of enduring individual and societal interest that has justifiably attracted considerable attention from researchers across the social sciences (Clark, Frijters, \& Shields, 2008; Kahneman \& Deaton, 2010). Consistently, research points toward there being a weak relationship (Lucas \& Dyrenforth, 2006), leading many to conclude that to improve people's lives we will have to go beyond focusing on money (Diener \& Seligman, 2004). However, one interesting research stream suggests that the weak relationship between money and happiness arises because people do not spend their money wisely (Dunn, Gilbert, \& Wilson, 2011). The implication being that more money would translate into greater happiness if people spent it "right"; for example, on experiences rather than possessions (Van Boven \& Gilovich, 2003), or on others rather than themselves (Dunn, Aknin, \& Norton, 2008). In line with this interesting and influential research stream, Matz, Gladstone, and Stillwell (2016) drew on a rich dataset of more than 76,000 bank transactions ( $N=625$ bank customers recruited from 150,000 invited to participate) to examine whether individuals who spend on goods that match their personality are more satisfied than those who do not. They then followed up with a study showing that students $(N=79)$ randomized into spending in line with their personality had higher levels of happiness. Their finding is important in that it further highlights the potential role of personality in moderating the influence of income and spending on well-being (Boyce, Wood, \& Ferguson, 2016; Soto \& Luhmann, 2013). However, the extent to which Matz et al. (2016) provided evidence that spending more money can buy happiness if it is spent "right", as implied by the article, is overstated.

In Study 1 Matz et al. showed that people spent more money on personality-matched products (Table 2) and that people who spent on personality-matched products have marginally higher life satisfaction (Table 3). However, it is impossible to link the two analyses because the second stage did not include the actual amount spent on personality-matched products. It therefore cannot be inferred that if spent "right" there would be a stronger relationship between levels of consumption and wellbeing or that the findings offer a "contrast to decades of research reporting surprisingly weak relationships between consumption and happiness" (Matz et al., 2016, p. 715). To evaluate whether support existed for this key idea it would have been necessary to examine whether the relationship between total spending and life-satisfaction was moderated by the strength of the match between the buyers' personality and their purchases. Crucially, the study did not do this.

Instead, the authors pointed to potential gains in life-satisfaction associated with personalitymatched purchases irrespective of the amount spent. To show this the authors calculated the difference between the personality z-scores (e.g. openness $=O$, neuroticism $=N$ ) of the participant $(i)$ and z-scores of the personality profile of the participants shopping basket $(b)$. They then rescaled this measure so that moving from low to high scores indicated a greater match between participants and basket personality scores (see equation 1 ): 
(1) basket participant match $_{i, b}=$ mean $-\sqrt{\left(z\left(O_{i}\right)-z\left(O_{b}\right)\right)^{2}+\cdots+\left(z\left(N_{i}\right)-z\left(N_{b}\right)\right)^{2}}$

However, it's not clear whether this somewhat complex matching variable captures meaningful variation in personality-matched purchasing. For example, participant and basket personality scores appear to be very weakly correlated (average $r=.05$, as shown in their supplementary Table S2) suggesting that few people tend to make purchases that closely match their personality. This led us to speculate that the only statistically significant link between personalitymatched spending and life satisfaction presented in the paper (Model 1, Table 3) could have been driven by participant personality, which is known to relate to well-being (Diener \& Lucas, 1999). Although we do not have access to the sensitive banking data used by Matz et al., we could generate a basket-participant match variable where participant and basket personality scores were similarly uncorrelated. We did this by matching randomly generated personality profiles for a participant's shopping basket to real personality data from participants in the English Longitudinal Study of Ageing (ELSA). We repeated this randomization 1000 times in a sample of equivalent size $(N=625)$ to Matz et al. to gauge the likelihood of detecting a spurious effect where one would not be expected. The results of our analyses are shown in Table 1 where we observe that greater basket-participant match positively predicts life satisfaction $(\beta=.12)$ as in Matz et al. (Model 1, Table 3). This occurred in $80.3 \%$ of our replications (where $p<.05$ ) and $100 \%$ of replications when the full ELSA sample $(N=7,990)$ was used. Whilst this analysis does not disprove the results of Matz et al, it highlights that it is difficult to precisely gauge what the matching variable used in the study is assessing given a similar pattern of results can be found when personality scores for purchases are randomly generated.

Nevertheless, even if the results are taken at face value they appear to show that attempting to spend one's way to happiness would "buy" so little well-being as to be largely irrelevant to people's lives. Standardized effect sizes are not provided, yet the R-squared values in their Table 3 suggest that the extent to which an individual spends in line with their personality explains less than $1 \%$ of the variance in life satisfaction. Income typically

Table 1

Average Results Based on 1000 Random Repetitions of Multiple Linear Regression Analyses Predicting Life Satisfaction Using Participant Personality Data From a Random Sample of the English Longitudinal Study of Ageing $(N=625)$ Matched to Randomly Generated Spending/Shopping Basket Personality Variables 


\begin{tabular}{lc} 
& $\begin{array}{c}\text { Satisfaction } \\
\text { (standardized) }\end{array}$ \\
\hline Basket-participant match & $\begin{array}{c}0.11^{* *} \\
(0.04)\end{array}$ \\
Household income (log) & $0.25^{* *}$ \\
& $(0.06)$ \\
Gender & -0.05 \\
& $(0.08)$ \\
Age & 0.00 \\
& $(0.00)$ \\
Percentage of random & $80.3 \%$ \\
draws in which basket- & \\
participant match is & \\
significant $(N=625)$ & \\
Percentage of random & $100 \%$ \\
draws in which basket- & \\
participant match is & \\
significant in the full & \\
sample $(N=7,990)$ &
\end{tabular}

Note: We randomly selected a sample of 625 of a possible 7,990 who answered all questions on life satisfaction, personality, and household income, in wave 5 of the English Longitudinal Study of Ageing. We then randomly generated personality z-scores for each participants "basket personality". We calculated the basket-participant match using the Euclidean distance following Matz et al. as follows:

$$
\left[\text { basket - participant } \text { match }_{i, b}=\text { mean }-\sqrt{\left(z\left(O_{i}\right)-z\left(O_{b}\right)\right)^{2}+\cdots+\left(z\left(N_{i}\right)-z\left(N_{b}\right)\right)^{2}}\right] \text {, }
$$

where i represents the participant z-scored personality and b represents the individuals (randomly generated) z-scored shopping basket personality characteristics. We then repeated this 1000 times with the results representing the average across the 1000 repetitions. We also carried out this analysis on the full ELSA sample. Standard errors in parentheses; ** $\mathrm{p}<0.01, * \mathrm{p}<0.05$.

explains at best $4 \%$ (Lucas \& Dyrenforth, 2006) and given that consumption expenditures are as important to life satisfaction as income (Headey, Muffels, \& Wooden, 2007) their results do not support the implication that the relationship is of meaningful magnitude. Thus, whilst money may buy happiness through consumption the conclusion should be, unless clearly demonstrated otherwise, that it buys so little it doesn't matter.

In contrast to this work, psychologists have identified several areas where money may matter to well-being. For example, income can help alleviate the psychological distress from poverty (Weich \& Lewis, 1998) and indebtedness (Gathergood, 2012). Further, low income rank appears to adversely influence well-being (Boyce, Brown, \& Moore, 2010) as does losing income (Boyce, Wood, Banks, Clark, \& Brown, 2013), particularly for those who value economic outcomes greatly (Boyce et al., 2016). However, even the magnitude of these robust effects tends to be dwarfed by the importance (as indexed by standardized effect sizes) of other factors such as relationships (Powdthavee, 2008), stable employment (McKee-Ryan, Song, Wanberg, \& Kinicki, 2005), and mental and physical health (Layard, Clark, Cornaglia, Powdthavee, \& Vernoit, 2014). Personality itself, irrespective of any 
interactive effect, has long been regarded as one of the strongest predictors of happiness (Diener \& Lucas, 1999). Indeed Matz et al. showed in their Table 3 that the main effects of neuroticism and extraversion are both far more important than any other variable in the study.

Given that Matz et al. (2016) showed the relative unimportance of consumption in providing people with greater happiness, regardless of how it is spent, it is a concern when it is implied that a consumption-based society can be a key route to greater happiness for all. Materialism is associated with less happiness (Dittmar, Bond, Hurst, \& Kasser, 2014) and there is a danger that if academics encourage people to pursue consumption with the hope of obtaining greater happiness, then individuals and policy makers may sacrifice pursuing the very things that are the most important to it. 


\section{References}

Boyce, C. J., Brown, G. D. A., \& Moore, S. C. (2010). Money and happiness: rank of income, not income, affects life satisfaction. Psychological Science, 21, 471-475. http://doi.org/10.1177/0956797610362671

Boyce, C. J., Wood, A. M., Banks, J., Clark, A. E., \& Brown, G. D. A. (2013). Money, well-being, and loss aversion: Does an income loss have a greater effect on well-being than an equivalent income gain? Psychological Science, 24, 2557-2562.

http://doi.org/10.1177/0956797613496436

Boyce, C. J., Wood, A. M., \& Ferguson, E. (2016). Individual differences in loss aversion: Conscientiousness predicts how life satisfaction responds to losses versus gains in income. Personality and Social Psychology Bulletin, 42, 471-84.

Clark, A. E., Frijters, P., \& Shields, M. A. (2008). Relative income, happiness, and utility: An explanation for the Easterlin paradox and other puzzles. Journal of Economic Literature, 46, 95-144.

Diener, E., \& Lucas, R. E. (1999). Personality and subjective well-being. In D. Kahneman, E. Diener, \& N. Schwarz (Eds.), Well-being: The foundations of hedonic psychology (pp. 213-229). New York, NY, US: Russell Sage Foundation.

Diener, E., \& Seligman, M. E. P. (2004). Beyond money: toward an economy of well-being. Psychological Science in the Public Interest, 5, 1-31.

Dittmar, H., Bond, R., Hurst, M., \& Kasser, T. (2014). The relationship between materialism and personal well-being: A meta-analysis. Journal of Personality and Social Psychology, 107, 879-924. http://doi.org/10.1037/a0037409

Dunn, E. W., Aknin, L. B., \& Norton, M. I. (2008). Spending money on others promotes happiness. Science, 319, 1687-1688.

Dunn, E. W., Gilbert, D. T., \& Wilson, T. D. (2011). If money doesn’t make you happy, then you probably aren't spending it right. Journal of Consumer Psychology, 21, 115-125. http://doi.org/10.1016/j.jcps.2011.02.002 
Gathergood, J. (2012). Debt and depression: Causal links and social norm effects. The Economic Journal, 122, 1094-1114. http://doi.org/10.1111/j.1468-0297.2012.02519.x

Headey, B., Muffels, R., \& Wooden, M. (2007). Money does not buy Happiness: Or does it? A reassessment based on the combined effects of wealth, income and consumption. Social Indicators Research, 87, 65-82. http://doi.org/10.1007/s11205-007-9146-y

Kahneman, D., \& Deaton, A. (2010). High income improves evaluation of life but not emotional well-being. Proceedings of the National Academy of Sciences, 107, 16489-16493. http://doi.org/10.1073/pnas.1011492107

Layard, R., Clark, A. E., Cornaglia, F., Powdthavee, N., \& Vernoit, J. (2014). What predicts a successful life? A life-course model of well-being. The Economic Journal, 124, 720-738. http://doi.org/10.1111/ecoj.12170

Lucas, R. E., \& Dyrenforth, P. S. (2006). Does the existence of social relationships matter for subjective well-being? In Kathleen D. Vohs \& Eli J. Finkel (Eds.), Self and relationships: Connecting intrapersonal and interpersonal processes (pp. 254-273). New York, NY, US: Guilford Press.

Matz, S. C., Gladstone, J. J., \& Stillwell, D. (2016). Money buys happiness when spending fits our personality. Psychological Science, 27, 715-725. http://doi.org/10.1177/0956797616635200

McKee-Ryan, F., Song, Z., Wanberg, C. R., \& Kinicki, A. J. (2005). Psychological and physical well-being during unemployment: a meta-analytic study. The Journal of Applied Psychology, 90, 53-76. http://doi.org/10.1037/0021-9010.90.1.53

Powdthavee, N. (2008). Putting a price tag on friends, relatives, and neighbours: Using surveys of life satisfaction to value social relationships. The Journal of Socio-Economics, 37, 14591480. http://doi.org/10.1016/j.socec.2007.04.004

Soto, C. J., \& Luhmann, M. (2013). Who can buy happiness? Personality traits moderate the effects of stable income differences and income fluctuations on life satisfaction. Social Psychological and Personality Science, 4, 46-53. http://doi.org/10.1177/1948550612444139 
Van Boven, L., \& Gilovich, T. (2003). To do or to have? That is the question. Journal of Personality and Social Psychology, 85, 1192-1202.

Weich, S., \& Lewis, G. (1998). Poverty, unemployment, and common mental disorders: population based cohort study. BMJ (Clinical Research Ed.), 317, 115-119. 